\title{
Duplicidad uretral incompleta
}

\author{
J. Rodríguez Tolrá, J.Mª Cuadrado Campaña, O. Buisan, A. Francés I Comalat,
}

E. Franco Miranda, N. Serrallach Milá

Servicio de Urología. Hospital Universitario de Bellvitge. L'Hospitalet de Llobregat. Barcelona.

Actas Urol Esp 2005; 29 (7): 697-699

\section{RESUMEN \\ DUPLICIDAD URETRAL INCOMPLETA}

La duplicidad uretral masculina es una malformación congénita poco frecuente. Presentamos el caso de un varón de 25 años con infecciones urinarias de repetición que fue diagnosticado mediante uretrografia retrógrada y cistouretrografía miccional de duplicidad uretral incompleta. El tratamiento consistió en la resección quirúrgica por vía perineal de la uretra duplicada incompleta. El resultado clínico fue excelente, quedando el paciente asintomático con funcionalidad uretral dentro de la normalidad.

Palabras clave: Uretra. Duplicidad uretral. Malformación congénita.

\section{ABSTRACT \\ INCOMPLETE URETHRAL DUPLICATION}

Urethral duplicity is a rare congenital malformation. We report a case of one 25 years old male suffering recurrent urinary infections. The diagnostic of uncompleted urethral duplicity was performed by retrograde urethrography and micturating cystourethrogram. The accessory channel was excised by a perineal approach. Clinical results were satisfactory, remaining an asintomatic patient two years after surgery, with normal mictional behavior.

Keywords: Urethra. Urethral duplication. Congenital malformation.

$\mathrm{L}^{\mathrm{a} a}$ a duplicidad uretral masculina es una malformación congénita poco frecuente. Ha habido numerosos intentos de clasificación, Stephens ${ }^{1}$, Cendron $^{2}$, Williams $^{3}$, Effman $^{4}$, Das $^{5}$, a pesar de lo cual sigue estando mal definida, ya que puede haber confusiones debido a la diferente terminología.

Embriológicamente la uretra bulbar no tiene un desarrollo uniforme en su longitud total, ya que corresponde al punto de fusión de los dos componentes del tabique urorrectal ${ }^{6}$ y es por esta razón por la que en ella se encuentra la mayor frecuencia de reduplicación uretral.

\section{CASO CLÍNICO}

Varón de 25 años operado de varicocele izquierdo hacia seis meses, que consultó por un problema de infecciones urinarias de repetición sin patología sexual. Se le practicó una uretrografia retrógrada y una cistouretrografía miccional que nos indicaron la presencia de una duplicidad uretral incompleta que nacía en la uretra bulbar y transcurría por la cara ventral (Fig. 1). Se procedió a la resección quirúrgica del trayecto accesorio por vía perineal (Figs. 2 y 3). Los controles de imagen posteriores mostraron la existencia de una uretra bulbar normal (Fig. 4). La sintomatología miccional no se ha vuelto a presentar en los dos años transcurridos desde la intervención.

\section{DISCUSIÓN}

La primera distinción que deberíamos realizar estaría entre la uretra duplicada y la uretra accesoria. La primera puede originarse en la vejiga, 


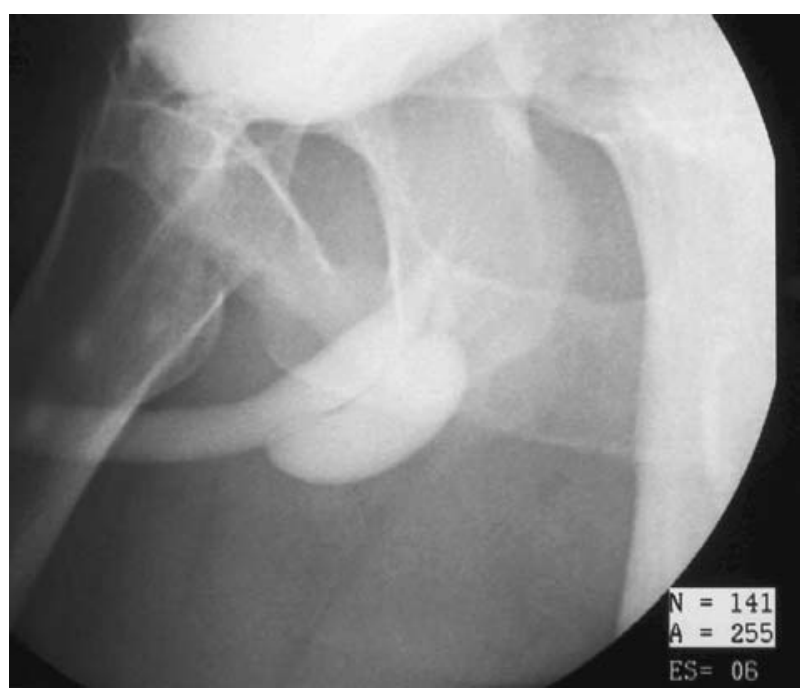

FIGURA 1. CUMS preoperatoria: Uretra accesoria incompleta.

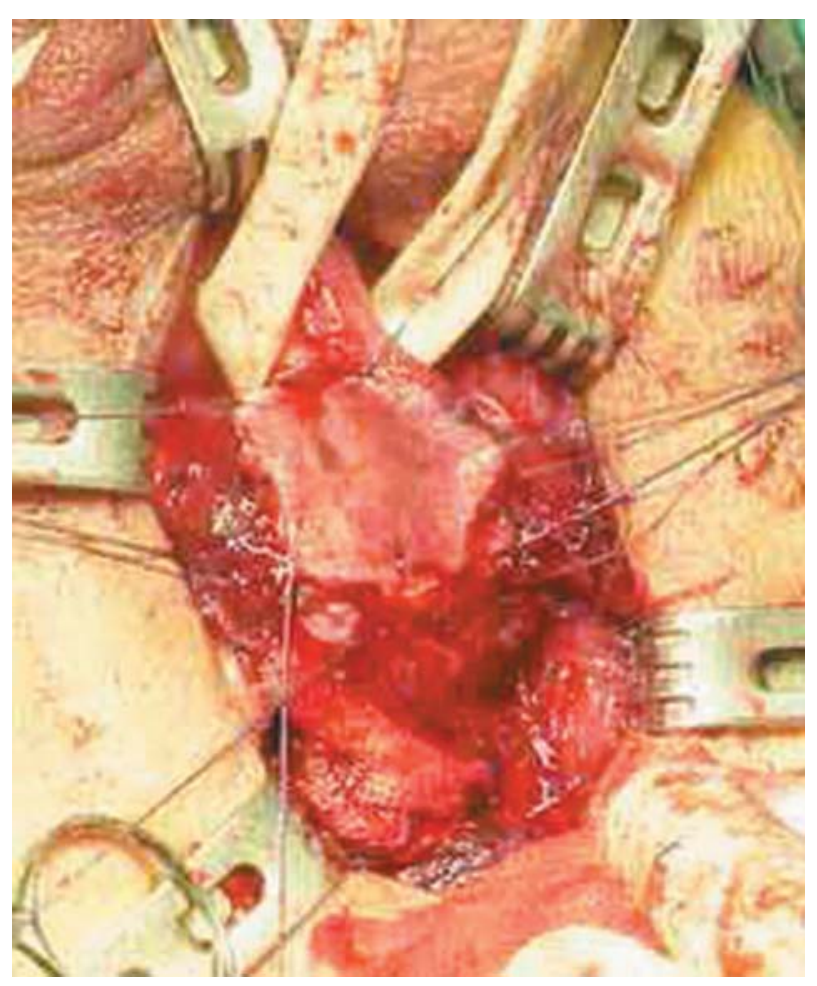

FIGURA 2. Uretra accesoria abierta en toda su longitud.

cuello vesical o uretra prostática, pudiendo ser completa si tiene salida el exterior a través de un orificio propio, o incompleta si se une nuevamente al conducto uretral normal. La uretra accesoria se originaría a partir de la uretra anterior y seria completa si se comunica con el exterior o incompleta cuando uno de sus extremos es ciego ${ }^{7}$. El

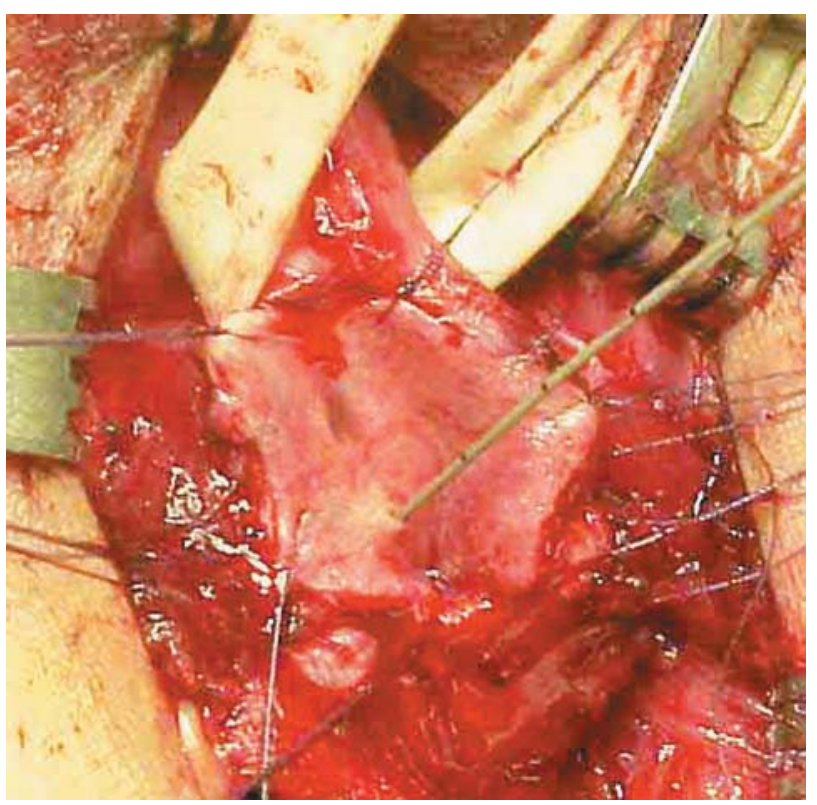

FIGURA 3. Orificio que comunica con la uretra normal cateterizado.

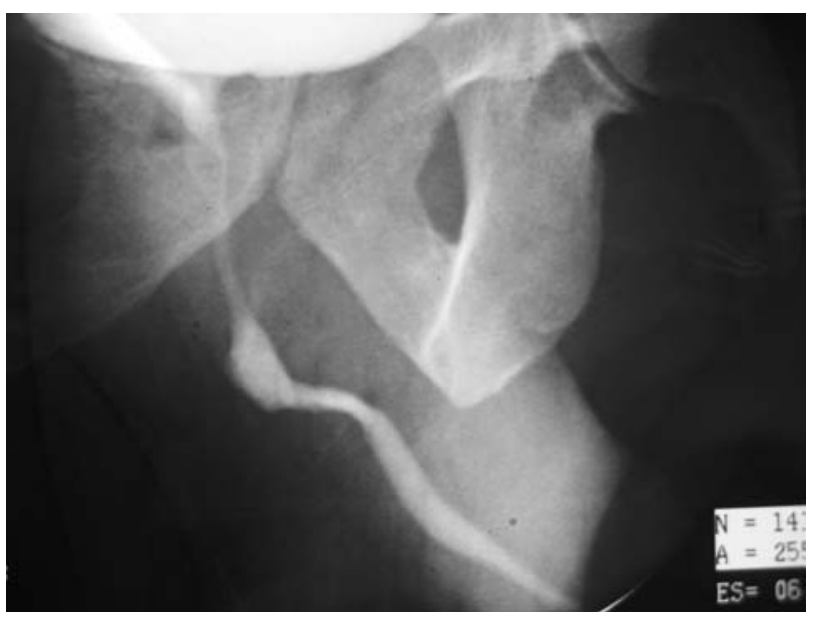

FIGURA 4. CUMS postoperatoria: Uretra normal con una zona irregular correspondiente al área de unión con la uretra accesoria.

paciente que nosotros presentamos sería una uretra accesoria incompleta según esta nomenclatura.

La presentación clínica dependería del tipo de duplicación. Las formas abiertas con un segundo meato epispádico o hipospádico serían fáciles de diagnosticar ${ }^{7,8}$, pero las formas ciegas, que son las más frecuentes, tendrían un diagnóstico más difícil. La sintomatología se podría agrupar según Barbagli ${ }^{9}$ en tres grupos: trastornos de la micción, trastornos sexuales y mixtos. 
Los trastornos de la micción más frecuentes serian: la infección recidivante, la incontinencia, el goteo postmiccional y la clínica obstructiva del tracto urinario inferior. Los trastornos de la función sexual vendrían manifestados por eyaculación disminuida o ausente.

El tratamiento de la duplicidad uretral es muy variable, ya que dependería del tipo de duplicidad y de la clínica asociada. Las opciones terapéuticas serían: la incisión endoscópica del tabique $^{10,11}$ o la uretroplastia en uno o dos tiempos. En lo que atañe a nuestro caso, creemos que la actuación correcta sería la exéresis total de la uretra accesoria y la reconstrucción del cuerpo esponjoso. También sería aconsejable una buena reconstrucción de los músculos bulbocavernosos sobre el segmento reconstruido para preservar la eyaculación anterógrada ${ }^{9}$.

Es evidente que el tratamiento quirúrgico sólo debe realizarse cuando la malformación provoca una sintomatología relevante, como en las infecciones urinarias de repetición que presentaba nuestro paciente.

En conclusión, las duplicidades incompletas de la uretra bulbar, son raras y con una sintomatologia escasamente indicativa de esta patología. El tratamiento iría encaminado a conseguir un canal uretral funcional con una reconstrucción meticulosa de todas sus capas.

\section{REFERENCIAS}

1. Cendron T, Desgrez JP. Uretres surnumeraires chez le garçon. A propos de 14 cas persormels. Ann Chir Infant 1975;16:409-413.

2. Williams DI, Kemawim H. Urethral duplications in the male. Eur Urol 1975;1:209-215.

3. Effmann EL, Lebowitz RL, Colodny AH. Duplication of the urethra. Radiology 1976;119:179-185.

4. Das S, Brosman SA. Duplication of the male urethra. J Urol 1977; 117:452-454.

5. Stephens FD. Congenital malformations of the urinary tract. Westport, Praege Publishers Division 1992; pp15-52.

6. Stephens FD. Congenital malformations of the urinary tract. Westport, Praeger Puplishers Division 1992; pp 3-14.

7. Ortolano V, Nasrallah PF. Urethral duplication. J Urol 1986;136:909-912.

8. Pippi Salle JL, Sibai H, Rosenstein D, Brzezinski AE, Corcos J. Urethral duplication in the male: review of 16 cases. J Urol 2000;163:1936-140.

9. Barbagli G, Selli C, Palminteri E, Tosto A. Duplicaciones de la uretra bulbar: hallazgos clínicos radiológicos y opciones terapéuticas. Eur Urol (Ed. Esp) 1996;Vol.3(3):229-233.

10. Goldstein HR, Hensle TW.Visual urethrotomy in management of male urethral duplication. Urology 1981;28:374376.

11. Melchor H. Duplication of the urethra-trans-urethral treatment. Eur Urol 1985;1:243-246.

Dr. J. Rodríguez Tolrá

C/ San Bruno, 31; $3^{\circ}-2^{\text {a }}$

08911 Badalona(Barcelona)

(Trabajo recibido el 4 de octubre 2004) 